\title{
INTERLOCUÇÕES DOCENTES SOBRE O CURRÍCULO DE EDUCAÇÃO FÍSICA: APLICABILIDADE, ELABORAÇÃO DEMOCRÁTICA E QUALIDADE EDUCACIONAL
}

\author{
Anderson Cristian BARRETO ${ }^{i}$ \\ Ana Luisa Barbosa ANVERSA ${ }^{\text {ii }}$ \\ Vânia de Fátima Matias SOUZA
}

\begin{abstract}
RESUMO
Base teórica: Sustentado nos pressupostos do materialismo histórico dialético, entende-se o currículo como sendo um constructo social, produzido por agentes sociais condicionados a um contexto históricosocial. Problema: Seria o currículo na prática, relevante e adequado as necessidades, na percepção dos professores de Educação Física? Objetivo: Verificar a importância curricular para as aulas de Educação Física, considerando as necessidades educacionais que se expressam e materializam no cotidiano. Metodologia: A aplicação de uma entrevista semiestruturada, aos 37 professores/as de Educação Física, resultaram nas categorias: Aplicabilidade Curricular, Elaboração Curricular Democrática e Qualidade Educacional. Síntese do estudo: A elaboração curricular de forma democrática efetiva-se na prática apenas quando se propõe a considerar a diversidade cultural e social dos agentes envolvidos.
\end{abstract}

PALAVRAS-CHAVE: Currículo; Educação Física Escolar; Professor.

\section{TEACHING INTERLOCUTIONS ON PHYSICAL EDUCATION CURRICULUM:} APPLICABILITY, DEMOCRATIC PREPARATION AND EDUCATIONAL QUALITY

\begin{abstract}
Theoretical basis: Based on the assumptions of historical dialectical materialism, the curriculum is understood to be a social construct, produced by social agents conditioned to a historical-social context. Problem: Would the curriculum in practice be relevant and appropriate to the needs, in the perception of Physical Education teachers? Objective: To verify the curricular importance for Physical Education classes, considering the educational needs that are expressed and materialized in daily life. Methodology: The application of a semi-structured interview to the 37 Physical Education teachers resulted in the following categories: Curriculum Applicability, Democratic Curriculum Development and Educational Quality. Summary of the study: Democratic curriculum development is effective in practice only when it proposes to consider the cultural and social diversity of the agents involved.
\end{abstract}

KEYWORDS: Curriculum; School Physical Education; Teacher.

\footnotetext{
i Pós-graduando em Educação: Políticas e Gestão Educacional. Professor de Educação Física da Educação Básica. Integrante do Grupo de Estudo e Pesquisa em Educação Física Escolar da Universidade Estadual de Maringá (GEEFE/UEM). E-mail: andercbarreto@ hotmail.com - ORCID iD: http://orcid.org/0000-0003-2944-2155.

ii Doutorado em Educação Física pela Universidade Estadual de Maringá (UEM). Professora do DEF/UEM. Email: ana.beah@gmail.com - - ORCID iD: http://orcid.org/0000-0003-4363-3433.

iii Doutorado em Educação pela Universidade Estadual de Maringá. Professora Adjunta do Departamento de Educação Física da UEM. Professora do Programa de Pós-Graduação em Rede em Educação Física UEM/UNESP. E-mail: vfmatias@ gmail.com - ORCID iD: https://orcid.org/0000-0003-4631-1245.
} 
INTERLOCUENCIAS DOCENTES SOBRE CURRICULUM DE EDUCACIÓN FÍSICA: APLICABILIDAD, PREPARACIÓN DEMOCRÁTICA Y CALIDAD EDUCATIVA

\section{RESUMEN}

Base teórica: Partiendo de los supuestos del materialismo dialéctico histórico, el currículo se entiende como un constructo social, producido por agentes sociales condicionados a un contexto históricosocial. Problema: ¿El currículo en la práctica sería relevante y adecuado a las necesidades, en la percepción de los profesores de Educación Física? Objetivo: Verificar la importancia curricular de las clases de Educación Física, considerando las necesidades educativas que se expresan y materializan en la vida diaria. Metodología: La aplicación de una entrevista semiestructurada a los 37 profesores de Educación Física resultó en las siguientes categorías: Aplicabilidad Curricular, Desarrollo Curricular Democrático y Calidad Educativa. Resumen del estudio: El desarrollo curricular democrático es efectivo en la práctica solo cuando se propone considerar la diversidad cultural y social de los agentes involucrados.

PALABRAS CLAVE: Plan de estudios; Educación Física Escolar; Maestro.

\section{INTRODUÇÃO}

A temática Educação Física (EF) e currículo vêm ganhando visibilidade no campo acadêmico. Autores como Tonieto e Garanhani (2017), Maldonado e Silva (2018), Neira (2018), Ponce (2018) e Pedon e Correa (2019) apresentam proposições inerentes ao currículo e a EF em suas pesquisas. Wiggers et al. (2015), Anversa et al. (2018) e Boscatto e Darido (2017) relatam dados sobre o crescimento dos estudos curriculares na área.

Dourado e Oliveira (2009), Silva (2009) e Fonseca (2009) retratam que a qualidade educacional brasileira está atrelada a fatores econômicos influenciados por organismos internacionais que medem o desenvolvimento por meio de avaliações quantitativas direcionadas ao desempenho, rendimento e eficiência do indivíduo. Dourado e Oliveira (2009), complementam que a qualidade da educação é um conceito polissêmico, multifatorial, com processo complexo e dinâmico, marcado por valores de credibilidade, comparabilidade, validade e incorruptibilidade, que proporcionam uma análise da situação escolar sem desconsiderar as dimensões intra e extraescolares.

Acreditamos que para uma educação de qualidade as diversidades e influências socioculturais devem ser consideradas, expressadas, materializadas e confrontadas com os conhecimentos e ações do espaço escolar, uma vez que cada manifestação ocorrida na escola e, em especial, nas aulas de Educação Física, carregam especificidades a serem valorizadas, 
Programa de Pós-Graduação em Educação: Currículo

trabalhadas e respeitadas, oferecendo um ambiente de aprendizagem significativa para além dos currículos escolares.

Enquanto documento educacional, o currículo, é compreendido como o orientador da prática docente, apontando os conteúdos a serem trabalhados junto aos alunos, na expectativa de aproximar o processo de ensino e de aprendizagem de suas realidades e necessidades. Hypólito, Vieira e Leite (2012) discorrem que trabalho docente e o currículo ainda estão submetidos às orientações conservadoras, com foco na eficiência e imediatismo como solução para os problemas da educação, desconsiderando as potencialidades trazidas pela comunidade escolar. Tais especificidades podem ser compreendidas pela forma que os currículos foram elaborados, com reduzida participação docente e recebendo intensas influências externas.

As reformas curriculares realizadas no Brasil nos últimos vinte anos denotam a intenção de formar cidadãos que possam construir uma sociedade menos desigual. Buscando coerência com tal propósito, não são poucos os sistemas e instituições de ensino que têm revisado objetivos de aprendizagem, conteúdos, práticas educativas e formas de avaliação. Portanto, nestes tempos em que democracia, justiça social, diálogo e inclusão são princípios basilares das políticas públicas em educação, é inconcebível a permanência de currículos que segregam, excluem e estigmatizam. A Educação Física corporifica essa tensão: enquanto algumas escolas e secretarias de educação conferem sobrevida às propostas convencionais, outras advogam alternativas condizentes com a contemporaneidade (NEIRA, 2018, p. 7).

A partir do ano de 2014, vivenciamos um movimento de expansionismo da escola pelo alargamento de tarefas e ampliação de funções descentralizadoras do trabalho docente, das especificidades do processo de ensino para conduzir as condutas dos sujeitos à inserção na sociedade (MACHADO; LOCKMANN, 2014). Esse processo está atrelado aos discursos que estabelecem relações hegemônicas produzindo, conduzindo e exercendo efeitos no trabalho do professor e percebida pela presença de pressupostos neoliberais, se inserem no currículo.

A estruturação curricular, com enfoque nos interesses de um determinado grupo, que conduz e gesta as questões políticas e educacionais a nível nacional, afeta as esferas educacionais a níveis federais, estaduais e municipais, fazendo com que a ação docente seja direcionada para um processo de formação de sujeitos que atendam as demandas econômicas vigentes.

Com a Resolução CNE/CP n. 2, de 22 de dezembro de 2017, a Base Nacional Comum Curricular (BNCC) é implantada dando direcionamento normativo as instituições de ensino da 
educação básica do país. Esse documento preconiza o desenvolvimento de habilidades intelectuais, afetivas, sociais e políticas e, para isso, os currículos devem ser organizados conforme as orientações prescritas no documento não se limitando aos conhecimentos, saberes e valores, mas ampliando a oferta de conteúdos que incentivem a aprendizagem de habilidades para que os sujeitos sejam, aprendam e façam escolhas, responsáveis e que conduzam suas vidas dentro das prerrogativas de cada época (MACHADO; LOCKMANN, 2014).

O currículo carrega em si interesses, "estratégias e orientações que traduzem a educação como responsabilidade que deve ser compartilhada por todos e a escola como um espaço que deve se ampliar para dar conta das diversas necessidades [...] em uma relação de imanência com a racionalidade política neoliberal" (MACHADO; LOCKMANN, 2014, p. 1600). Por isso, esse deve ser pautado em concepções que promovam conhecimento, diálogo, compreensão, respeito e consideração ao processo histórico social de todos os sujeitos e culturas existentes e não a formação de indivíduos voltados a um modo de ser específico.

Concordamos com Palma, Oliveira e Palma (2015) de que o currículo é um constructo social, produzido por agentes sociais, sem neutralidade, inseridos e condicionados a um contexto histórico-social. A EF, enquanto disciplina escolar fundamenta-se por dimensões motoras, culturais, sociais, políticas e afetivas construídas historicamente, representada e manifestada por meio de práticas corporais (PC) como os esportes, danças, ginásticas, jogos, brincadeiras, lutas e práticas corporais de aventura, entendidas como cultura corporal do movimento (CCP) e sua ação prática se organiza pelo currículo. Saviani (2008) e Gama e Duarte (2017) apontam que o currículo é um conjunto de atividades nucleares desenvolvidas pela escola que contém as atividades essenciais que não podem deixar de se desenvolver, podendo perder sua especificidade. Assim, reflete uma relação em que os conteúdos curriculares estabelecem conjuntamente com as práticas pedagógicas, a ação de suprir as necessidades dos alunos.

Orientando o trabalho docente, o currículo permite que o professor realize sua ação pedagógica de forma a proporcionar aos alunos acesso ao conhecimento. Scherer e Graff (2017) apontam que devemos destituir do currículo uma certa rigidez e alternar para uma forma mais flexível, permitindo alterações de objetivos e estratégias que se convertam em ações visando o atendimento das necessidades e interesses dos alunos. Acrescentamos que os interesses possam 
vir de toda comunidade escolar, desde que se voltem para ampliar e enriquecer o desenvolvimento dos aspectos de ensino e de aprendizagem.

Frente ao exposto, indaga-se como um currículo de Educação Física, elaborado por determinado grupo social, frente da gestão educacional, se torna importante e qualitativo para os professores de Educação Física atuantes na escola, local em que as ações expressarão o conteúdo incorporado ao documento, se tornando aplicável ou não para a realidade escolar? Deste modo, o presente estudo tem por objetivo verificar a importância que o documento proporciona para a melhoria ou não das aulas de Educação Física do ensino fundamental anos iniciais, considerando às necessidades educacionais que se expressam e materializam no cotidiano.

\section{ASSEPÇÕES METODOLÓGICAS}

Para os desvelamentos que implicam a compreensão da realidade apresentada, parte-se do entendimento de que o trabalho docente em Educação Física é regido por um documento orientador das ações pedagógicas no cotidiano escolar. O currículo escolar da educação básica brasileira, representado atualmente pela BNCC (BRASIL, 2017) resulta de intensos debates educacionais e políticos com viés a uma adequação e homogeneização da estrutura educacional e das práticas docentes em sala de aula.

A nova formatação curricular, garantida pela BNCC, provoca complexas interpretações e, como menciona Santos (2018), a complexidade de cada contexto que estamos imersos é transitória, sincronizada com situações de defasagem de relações, se torna confuso compreender e percorrer os caminhos, assim é necessário voltar à simplicidade das coisas. A pesquisa aqui apresentada, ocorreu no processo de transitoriedade curricular, causando diversos e intensos diálogos sobre a inserção da BNCC. O currículo vigente nesse período, estava formatado e embasado pela Teoria Histórico Cultural e pela Pedagogia Histórico Crítica.

Para compreender essa estrutura foi necessário conhecer e ampliar o entendimento da essência do objeto, Duarte (2008), refere-se a essa forma de compreensão como o estágio de maior desenvolvimento não se apresentando ao pesquisador imediatamente, mas mediatizada, por meio de interlocuções realizadas durante o processo analítico e de suas abstrações. 
Dialeticamente a apropriação do concreto pelo pensamento científico ocorre na mediação do abstrato em três momentos: a síncrese, a análise e a síntese. Sem mediação e análise o pensamento científico não supera a síncrese (senso comum) e não atinge a síntese (compreensão da realidade total e concreta).

Ao analisar o currículo da Educação Básica da rede municipal de uma cidade do noroeste do Paraná, notou-se a existência de um currículo antagônico e, por isso, buscou-se por meio do método qualitativo do tipo descritivo, dar vozes aos docentes atuantes na educação básica, de modo a extrair, aprofundar e compreender o que puderam e quiseram expressar sobre a relação do documento com a realidade escolar e das aulas e, assim, materializar seus pensamentos.

Participaram do estudo 37 professores de educação física da rede pública de ensino municipal, sendo 26 do sexo feminino e 9 do sexo masculino, com idade entre 23 e 51 anos, e com tempo de atuação na carreira pública municipal de 01 e 20 anos. Todos possuem formação acadêmica em nível de pós-graduação, sendo 33 profissionais diplomados na modalidade Lato Senso e 02 Strictu Sensu. Os locais de trabalho dos professores estão situados na zona urbana do munícipio e as escolas possuem recursos físicos, materiais e tecnológicos que favorecem o desenvolvimento de aulas teóricas e práticas.

O critério de participação para pesquisa foi a voluntariedade. Os professores participaram de um curso de formação continuada oferecido pela secretaria municipal de educação e o espaço e tempo foi cedido para que a coleta de dados ocorresse antes de iniciar a formação continuada sobre currículo. Por meio de autorização junto a coordenação de Educação Física e mediante a assinatura do Termo de Consentimento Livre e Esclarecido (TCLE), os dados foram coletados em uma entrevista semiestruturada, elaborada por meio de uma matriz analítica a partir dos objetivos e indicadores traçados para a pesquisa.

Os dados foram tratados a partir dos indicativos da análise de conteúdo (MINAYO; DESLANDES; GOMES, 2016), adotando a categorização, inferência, descrição e interpretação dos dados, estruturados pela decomposição em partes do material coletado, distribuídos em categorias, descritos e interpretados com apoio cientifico teórico. O material adquirido, durante a análise foi subdividido em ordenação, classificação e análise propriamente dita com condução do tratamento dos dados à teorização, produzindo o confronto entre a abordagem teórica e a investigação de campo. Após esse processo, foram obtidas 03 categorias para análise. São elas: 
Programa de Pós-Graduação em Educação: Currículo

Aplicabilidade Curricular; Elaboração Curricular Democrática e Qualidade Educacional e Curricular. Ressalta-se que o estudo tem autorização junto ao comitê de ética por meio do parecer n.1.715.040.

\section{O QUE DIZEM OS PROFESSORES}

Para melhor compreensão, os resultados da pesquisa foram organizados em categorias e subcategorias analisadas e discutidas sequencialmente conforme a figura 1 apresenta.

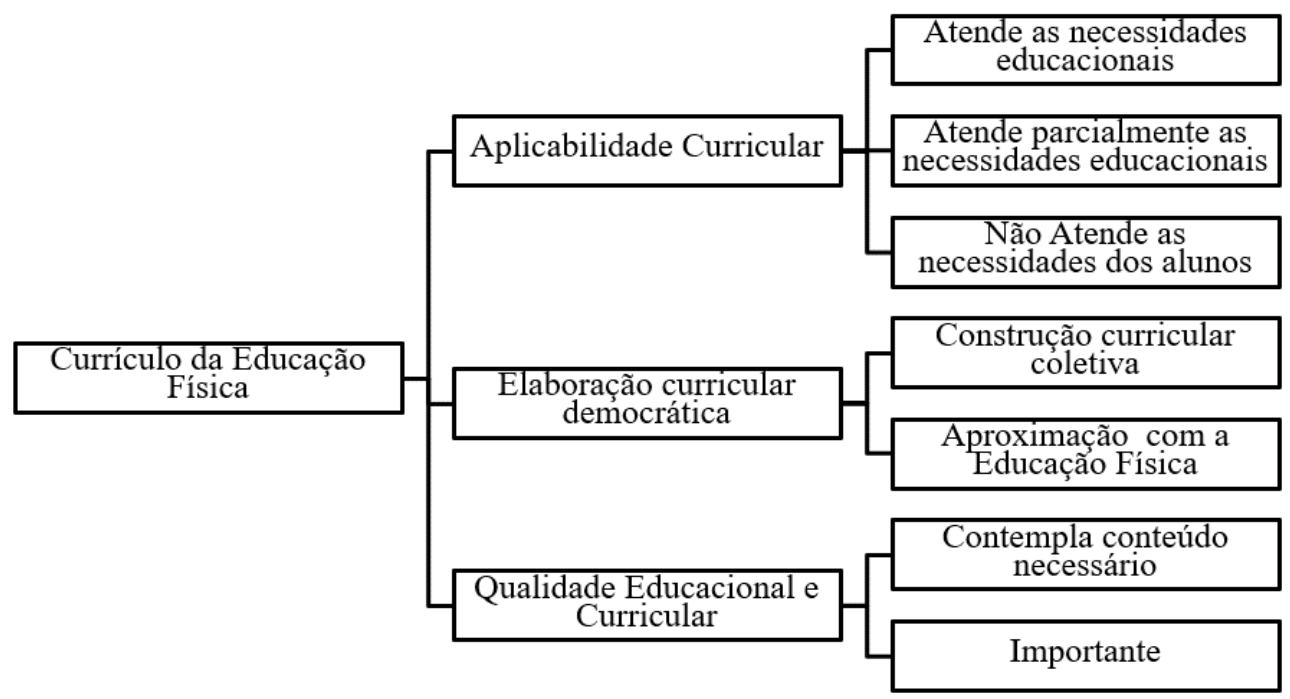

Figura 1 - Categorias e subcategorias identificadas e analisadas nas falas dos professores Fonte: os autores.

\subsection{Aplicabilidade curricular}

Os apontamentos trazidos nas falas dos docentes indicam que o currículo atende as necessidades educacionais dos alunos, uma vez que o documento abrange os conteúdos inerentes a cultura corporal do movimento, direcionando as ações para o desenvolvimento infantil com ênfase nos aspectos motores.

Soares et al. (2012) discorrem que a Educação Física, enquanto prática pedagógica, tematiza manifestações corporais por meio da dança, esporte, lutas, ginástica e jogos, se configurando em uma cultura corporal do movimento que, no ambiente escolar, é tratado 
enquanto conhecimento construído e referenciado por questões filosóficas, cientificas, políticas e culturais. Observa-se nas falas dos professores que o currículo "abrange o conteúdo da área" (P2), "transmite o conhecimento historicamente construindo" (P22) e "resgata o conhecimento culturalmente construído pela cultura corporal do movimento" (P33).

A disciplina de Educação Física no âmbito escolar, constituída pelos diferentes aspectos que envolvem o movimento corporal, rompe inúmeros paradigmas referente às manifestações práticas que a compõe, agregando novos valores. Influenciada, composta e organizada de acordo com os contextos socioculturais a qual se insere, permite a materialização de gestos corporais que retrata o conhecimento e a cultura de uma sociedade.

O currículo deve acompanhar o desenvolvimento da sociedade e considerar todos os aspectos necessários para a formação do sujeito. Na fala de um dos professores identifica-se, que o documento "vem sendo estudado e adaptado durante os anos" (P31). Esse apontamento vai ao encontro do indicado por Tonietto e Garanhani (2017) ao destacarem que o processo educacional se constrói constantemente e deve ser (re)pensado a partir dos envolvidos na prática pedagógica, considerando os conhecimentos trazidos pelas crianças em forma de expressão, possibilitando ao professor agregar e utilizá-la como recurso pedagógicas.

Uma vez que o currículo permite ao docente desenvolver com autonomia tal conhecimento, concomitantemente possibilita o desenvolvimento da criança de maneira ampla, conectando-a aos conhecimentos. Possibilitar que a criança manifeste seu conhecimento por meio do movimento, é propiciar o desenvolvimento e enriquecimento de sua cultura corporal. Para tanto, Palma, Oliveira e Palma (2015) retratam o currículo como um documento contribuidor para a formação dos alunos, por possibilitar a transmissão de saberes e formação de hábitos, atitudes, habilidades, valores e convicções.

A construção curricular para Perini e Bracht (2016), baseia-se em aspectos particulares da criança, considerando sua faixa etária com perspectiva de uma aprendizagem gradativa e com a inserção dos conteúdos adaptados em relação às suas capacidades e conhecimentos, imprimindo sentido e significado ao que se concretiza na prática. Para Neira e Nunes (2009) o currículo tem que ser encarado como instrumento de constituição de sujeitos, tomando como referência o patrimônio cultural corporal popular, possibilitando a construção e o reconhecimento dos alunos no processo de desenvolvimento. 
A apropriação do conhecimento para a criança, transmitido e mediado pelo professor, ocorre de maneira singular. As manifestações corporais trazidas para dentro da escola reforçam o desenvolvimento dos aspectos motores e considera todo o processo histórico que o movimento traz. Para os professores entrevistados o currículo prioriza o desenvolvimento dos aspectos motores das crianças, "nele envolve os principais conteúdos para o desenvolvimento motor" (P16), "contempla todas as áreas essenciais do desenvolvimento motor da criança" (P24), "os alunos necessitam aprender, desenvolver e aprimorar as habilidades motoras e neuromotoras" (P26) e "abrange todas as condutas necessárias para a faixa etária” (P15).

Um currículo que considera e valoriza os aspectos peculiares das crianças, permitindo sua participação na ressignificação dos conteúdos por meio de conhecimento adquirido nos diversos contextos que vivencia fora da escola, se torna um valioso instrumento para o processo de ensino e de aprendizagem, permitindo ao docente aproximação da realidade e das necessidades dos educandos e, consequentemente, refletindo no desenvolvimento do aluno, atendendo as necessidades no processo formativo. Deve ser organizado de forma em que os conteúdos sejam significativos, gradativos e coerentes com cada ano escolar e a idade do aluno, abrangendo não somente os aspectos motores, mas sim demais aspectos essenciais para que a criança se desenvolva.

Outros professores disseram que o currículo atende parcialmente as necessidades educacionais dos alunos, tendenciando para um não atendimento. Nas falas dos atores identificamos que os conteúdos são repetitivos, não são trabalhados na integra e quando são, ficam superficiais ao aluno, não contemplando as manifestações corporais contemporâneas. As formas em que as aulas são organizadas dificultam o trabalho, a disciplina Educação Física não interage com outras e o aluno não é considerado em sua integralidade.

Um professor apontou que o currículo atende "pois vem estruturado em uma metodologia e em uma fundamentação coerente" (P18). Indo ao encontro dessa explanação, Mota e Silva e Venâncio (2015) mencionam que a prática educativa da Educação Física Escolar deve ir ao encontro de objetivos definidos nas propostas pedagógicas e ao mesmo tempo utilizar os conhecimentos da cultura corporal do movimento de maneira sistematizada.

Em relação aos conteúdos serem repetitivos, não serem trabalhados na integra e quando são, ficam superficiais aos alunos, os professores manifestaram que "todo ano ele se repete por 
completo" (P11), "ele é meio repetitivo e não contempla outros conteúdos" (P29), "os conteúdos acabam sendo geridos superficialmente" (P34).

Sobre isso, nas palavras de Palma, Oliveira e Palma (2015), na elaboração curricular deve-se apresentar conhecimentos necessários para formar um indivíduo, reunindo ensinamentos valiosos para o aluno, se constituindo pela interação dos temas abordados, desde o mais simples até o mais complexo, promovendo maior interesse do educando e aumentando a significatividade do que se aprende. Marani, Sanches Neto, Freire (2017), em uma proposta curricular, consideram positiva a adequação do currículo ao aluno, com diversificação e sequência de temas propostos, para implementar numa rede de ensino pública.

A organização curricular deve ser progressiva e pautada nas necessidades dos alunos. Sua constituição necessita atender as demandas que a criança carece, pois "é de suma importância, visto que, propõe uma ordem sequencial de conteúdos que teoricamente vai de acordo com a faixa etária do aluno, respeitando suas limitações e capacidades" (P31). A construção do saber para Matos et al. (2015) se realiza na relação com um conteúdo que tem significado para o aluno, de modo que ele atribua sentidos ao que é ensinado, deixando vestígios e produzindo efeitos, permitindo ao aluno mobilizar-se em diferentes contextos, apropriando e incorporando o que foi ensinado,

Possibilitando o aprofundamento na temática apresentada pelo professor, para que o processo de ensino e de aprendizagem seja mais efetivo, a organização curricular é essencial, assim "o currículo é um parâmetro que nos norteia para a nossa prática docente" (P30). Conteúdos excessivos e repetitivos acabam se tornando irrelevante para o aluno e inviabiliza a qualidade das aulas, refletindo, nos envolvidos no processo, frustração e desinteresse. Marani, Sanches Neto e Freire (2017), apontam que professores defendem a existência de um currículo para uma rede de ensino pública, desde que permita trazer coesão ao trabalho realizado com os alunos, reorganizando os conteúdos para o tratamento de temas específicos, evitando se desconectar das necessidades educacionais.

O currículo deve estar em constante análise, permitindo sua atualização e adequação para a realidade escolar, se aproximando daquilo que os alunos precisam para progredirem em seu desenvolvimento, "seguindo os conteúdos pertinentes a cada faixa etária dos alunos, com conhecimento científicos e também com os conhecimentos prévio dos alunos" (P29), sendo "a base de formação do educando e do processo de aprendizagem" (P27), "é um instrumento capaz 
de nortear e subsidiar a ação docente para alcançar os objetivos para o desenvolvimento da criança, como também um compilado de conteúdos tornando-se importante a partir do momento em que for bem formulado e aplicado para alcançar os reais interesses educativos e não somente para ser bonito no papel" (P22).

O desenvolvimento do aluno é possibilitado por meio das vivencias práticas trazidas pelo professor. Compreende-se que "as práticas corporais devem ser abordadas como fenômeno cultural dinâmico, diversificado, pluridimensional, singular e contraditório" (BRASIL, 2017, p. 209). Assim, os docentes mencionam que o documento curricular não contempla manifestações corporais contemporâneas, sendo delegado ao "docente conseguir de forma organizada transmitir o maior número de conhecimentos de forma variada e com qualidade e tal conhecimento, construído historicamente, servirá de base para a construção de novos conhecimentos e de uma nova prática social” (P5)

No currículo se insere os conteúdos e temas a serem transmitidos aos alunos, compondo seu processo formativo, devido a sua importância para as ações nas aulas "os conteúdos facilitam a prática pedagógica do professor, pois é através deles que as informações são transmitidas na especificidade de cada turma" (P3). Entretanto, novas configurações sociais emergem diante da realidade de cada comunidade escolar e o currículo deve ser flexível em acompanhar tais transformações. Gonzales, Darido e Oliveira (2014), apontam que pensar em práticas corporais indica que o professor se atente as diversas temáticas que podem ser estimuladas para além das estruturas básicas que as compõem.

Ampliar e atualizar as abordagens nas aulas de Educação Física é fomentar o desenvolvimento das crianças ao encontro de suas necessidades. Gonzales, Darido e Oliveira (2014) inferem que vivenciar diferentes manifestações da cultura corporal enriquece e estimula momentos de discussões sobre organização social, regras e normas, a relação e envolvimento com a qualidade e estilo de vida, a manifestação cultura humana atrelada ao tempo livre, as formas de se relacionar com o meio ambiente e social e demais aspectos reflexivos nas atividades permissores de transcendência do caráter individualizado e simplificado dos campos de conhecimento.

Para Anversa e Souza (2016) as aulas de Educação Física devem ser um momento de promoção em suas relações, rompendo com a reprodução do sistema, ressaltando a amplitude advinda de direcionamentos intelectuais e morais, pois nas aulas as ações práticas estão ligadas 
ao processo formativo educativo, reconhecendo as perspectivas históricas do mundo. Conhecer e reconhecer os processos históricos que compõem as manifestações corporais nas aulas de Educação Física é para Gonzales, Darido e Oliveira (2014, p. 14) “oportunizar acesso a saberes, conhecimentos, vivências, experiências e atitudes que potencializam atingir objetivos" propostos para o desenvolvimento da criança relacionadas as demandas de seu contexto sociocultural.

Permitir que as crianças se aproximem de práticas contemporâneas, principalmente aquelas vivenciadas em seu cotidiano, sob a mediação e orientação docente é em acordo com Anversa e Souza (2016) reconstruir os saberes e conhecimentos na realidade do contexto escolar, articulando prática docente e a realidade social, pois é na aula que se pressupõe que o professor tenha dimensão da realidade tratada, por meio da reflexão pedagógica, permitindo integração e identificação do indivíduo no sistema social, "legitimando todo o conteúdo desenvolvido nas escolas a partir do planejamento construído" (P14).

Para tanto é necessário que as aulas de Educação Física sejam estruturadas e organizadas de modo a possibilitar a contemplação de novas abordagens práticas e "é o currículo, documento onde deve constar todos os conteúdos a serem desenvolvidos pelos professores aos educandos durante a formação da educação básica, servindo de base para o desenvolvimento integral do indivíduo (P01). Ao mencionarem que organização das aulas dificulta o trabalho, pressupõe que a dinâmica escolar, especificamente as aulas de Educação Física, sejam revistas para propiciar a efetivação da proposta da disciplina escolar.

González e Schwengber (2012) trazem à cena que a Educação Física, enquanto disciplina dedicada ao conhecimento das práticas corporais sistematizadas depende de um espaço tempo dedicado ao conhecimento do ato de movimentar-se, pois conforme a criança cresce e se desenvolve, a experiência do movimento se torna insuficiente em si. O currículo organizado de forma esquematizada auxiliará o professor a conduzir os conteúdos pertinentes a cultura corporal do movimento ampliando as vivências corporais do educando (P21), que se aproximem de sua realidade e dando sentido para a criança.

A organização das aulas possibilita facilita a apresentação dos conteúdos para os alunos e trabalho do professor, com segurança. "Levando em consideração o tempo da hora/aula e a quantidade de conteúdo a ser aplicado, qualitativamente perde-se a proposta curricular, visto que os conteúdos acabam sendo abordados superficialmente. Neste aspecto, há necessidade de 
reformulação do currículo, de forma que o torne mais efetivo sua aplicabilidade, prezando pela qualidade" (P34).

Arroyo (2007) enfatiza que o currículo, seus conteúdos, sua forma ordenada, sequencial, hierarquias e cargas horárias são o núcleo constituinte do cotidiano, tempo e espaço escolar. Organizar uma proposta curricular requer profundo conhecimento da realidade socioeconômica da comunidade, possibilitando adequações e reconstrução do documento pedagógico adequado aos alunos. A disciplina Educação Física se caracteriza por possuir uma abordagem e prática pedagógica distinta das demais disciplinas escolares e, mesmo assim "não conquistou seu espaço de forma plena no ambiente escolar, pois ainda não dialoga com outras disciplinas e, quando discute, são questões sociais (P18).

A não interação da disciplina com as demais, é resultante das relações entre o corpo docente. A ausência de diálogos e trabalho isolado, contrariam as propostas pedagógicas de interação entre os agentes escolares, distanciando-os. Rufino (2017) discorre que o currículo elaborado por profissionais distantes da realidade do ambiente escolar, gera forte implicação no trato do professor com a organização e desenvolvimento de seu trabalho, pois desconhecendo as possibilidades de atuação, o docente se afasta das possibilidades que a cultura corporal do movimento oferece por possuir diversidade e pluralidade para as manifestações corporais, dificultando o aprofundamento das temáticas que a envolvem, impedindo "a formação do ser humano na sociedade" (P20).

Pensar em uma estrutura curricular que contemple a interação entre as disciplinas é favorecer e otimizar o desenvolvimento do processo ensino aprendizagem. Dourado e Oliveira (2009) apontam que os processos educativos e, consequentemente, os resultados escolares, de forma significativa, resultam de ações concretas com o objetivo de democratização dos processos [...] de planejamento pedagógico. Entende-se que os professores, diante de um currículo individual, devam agir de forma a trabalhar coletivamente se adequando as necessidades apresentadas pelos alunos.

Interagir e trabalhar em conjunto é essencial para o sucesso pedagógico, pois "as aulas precisam ser bem planejadas e estarem adequadas as temáticas, envolvendo a todos e que nesses momentos os esclarecimentos transcendam a individualização dos diferentes campos de conhecimento" (GONZALES, DARIDO; OLIVEIRA, 2014, p.14). Diante isso, alicerçar as ações docentes interventivas, para Anversa, et.al. (2018b), se faz necessário para que sua 
atuação no contexto escolar centre nas práxis coletivas, oportunizando o acesso a diversidade de conhecimentos, contribuindo e ampliando as possibilidades de construir novos saberes. $\mathrm{O}$ aluno deve ser considerado de forma integral na estruturação do currículo e planejamento escolar.

Diante das especificidades de cada aluno, cada comunidade escolar também é ímpar em sua constituição, assim deve-se considerar essa singularidade para o estabelecimento de propostas que permita a ação pedagógica voltada e centrada no desenvolvimento do aluno, com ações pedagógicas direcionadas diretamente a necessidade que a criança precisa no espaço escolar. Para Anversa et al. (2018b), é necessário considerar a ação profissional levando o professor a deparar-se com diversas situações, as quais permitirão uma ação interventiva focada no diálogo, possibilitando a construção de novas formas e perspectivas de perceber e (re)agir, considerando as particularidades do aluno.

Diante das peculiaridades trazidas para o atendimento das necessidades educacionais dos alunos, nos deparamos com questões inerentes ao não atendimento das necessidades. Os professores manifestaram que o conteúdo é excessivo e repetitivo e a carga horária e conteúdos divergirem da fase de desenvolvimento, igualando aos anseios apresentados em categorias analisadas anteriormente e confirmando que ambos entrevistados anunciam características do documento que precisam ser otimizadas para melhorar a qualidade do trabalho docente.

Assim, os entrevistados manifestaram "que o currículo tem muito conteúdo para poucas aulas, nós professores da rede municipal não temos tempo para assimilar, aprofundar e vivenciar sua prática pedagógica entre docente e discente. O correto é ter um currículo com menos conteúdos e englobar os fundamentos teóricos nas aulas, tornando-se mais cientifico, prazeroso e pedagógico (P04)". "Falta especificidade para o atual currículo que fala de tudo, porém não traz especificidade de nada. Muita generalização, um currículo conteudista, com pouco tempo para se fazer na prática com os alunos (P32).

A Educação Física, na BNCC (BRASIL, 2017), deve oferecer possibilidades enriquecedoras para a experiência do aluno na educação básica, possibilitando-o acessar o universo da cultura corporal compreendido por saberes corporais, experiencias estéticas, emotivas, lúdicas e agonistas, se inscrevendo sem se restringir a racionalidade cientifica orientadora das práticas pedagógicas escolares. 
Entretanto, a investigação identificou, pelas expressões dos professores que carece de organização sistematizada, progressiva e atualizada, apresentando extensa repetição de conteúdos de modo que um tema seja trabalhado em todos os anos. Está ocultada a organização progressiva dos temas e o documento não apresentou práticas corporais como esporte de aventura (skate, parkour etc.) e danças urbanas (street dance, hip hop, funk) que se caracterizam por seu ineditismo nas abordagens corporais e estão presentes no cotidiano dos alunos.

\subsection{Elaboração curricular}

A EF enquanto disciplina escolar é para Maldonado e Silva (2018), uma múltipla prática de manifestações da Cultura Corporal do Movimento, pela qual os seres humanos se comunicam e transformam o movimento em linguagem, com características coletivas próprias, (re)criando seu estilo, expressando sua cultura e elaborando novos códigos comunicativos. Essa propositiva oportuniza refletir sobre a construção curricular coletiva, permitindo aproximar a comunidade escolar do conhecimento inerente as aulas de EF e de sua ação educativa.

Brasil $(2015 ; 2017)$ retrata à educação na qualidade de processos formativos desenvolvidos em convivência familiar e social, no trabalho, nas instituições de ensino, nas relações criativas entre natureza e cultura, reconhecendo compromisso para desenvolver o indivíduo em suas dimensões intelectual, física, afetiva, social, ética, moral e simbólica. Os aspectos constitutivos do termo educação são essenciais para a constituição das relações sociais e formação da criança.

A participação da comunidade escolar, orientada à constituição das ações escolares são colaborativas. Os docentes apontam que a "contribuição de todos é importante no desenvolvimento e construção" (P04) “aproximam as necessidades regionais e culturais" (P12), a "construção coletiva pode vir a favorecer alguns regionalismos e costumes" (P20), "a participação de todos oferecem conhecimentos, pois estão relacionados a realidade social" (P21), "a comunidade escolar pode adequar, sugerir, planejar e estruturar o currículo de acordo com a realidade"(P28), "a construção educacional deve ser feita democraticamente"(P30) e "para que se contemple uma educação de qualidade"(P33). 
O currículo democrático inclui a participação da família do aluno em sua elaboração e "atribui mais comprometimento dos familiares" (P30). Silveira e Britis (2017, p. 90) afirmam que "a relação entre escola e família é fundamental quando o foco passa a ser o desenvolvimento pleno do estudante", tais instituições devem unir-se para garantir o acesso à educação e o desenvolvimento da criança. Os alunos são orientados ao conhecimento científico pelos docentes, agregado pela participação familiar, às ações educativas tendem a se potencializar, indo ao encontro das especificidades da criança.

A participação familiar, atrelada à elaboração curricular, agrega benefícios ao desenvolvimento da criança, pois enquanto documento indicador de conteúdos escolares, o currículo propicia acesso ao conhecimento, apresentando novas formas de interpretação dos saberes construídos historicamente. "A comunidade escolar funciona como um tripé para sustentar a educação das crianças. Sendo assim, se torna importante contribuir na construção do currículo a fim de entender e elaborar de acordo com as necessidades de cada região, para continuarmos aprendendo e colaborar com a sociedade" (P06).

Silveira e Britis (2017) referem-se à relação escola-família como complexa, envolvendo saberes, experiências e expectativas diferentes concernentes a educação, refletindo, pela participação ativa, a capacidade democrática de construir, de forma dialética, uma educação comprometida, consciente e inclusiva de estudantes e familiares na dimensão escolar e "por meio da comunidade e dos professores é possível fazer um elo de ligação entre os alunos, atendendo a necessidade de todos" (P10).

Outro aspecto importante é de que "os alunos precisam ser ouvidos, uma vez que o currículo é para eles. O aprendizado é melhor quando há o interesse deles nas aulas” (P11). Para que o aluno acesse o conhecimento histórico é necessário, conforme indicam De Paula et al. (2015) adequação curricular que demanda atender toda a comunidade escolar e sua diversidade. Para isso, Rosário e Darido (2005) afirmam ser importante proporcionar aos professores conhecimentos e reflexões sobre organização dos conteúdos das aulas de EF e a escola tornase responsável pela implementação do currículo oficial e ação protagonizada dos professores (PEDON; CORREIA, 2019, p. 85).

Cabe aos professores, identificar e mensurar quais especificidades serão necessárias contemplar, possibilitando a otimização do processo educativo associado a comunidade escolar. Considerando a especificidade de cada escola, bairro, comunidade, nem todos queiram 
participar e nem todos têm condições para contribuir com a elaboração, mas caso acontecesse, seria interessante, contribuindo sim (P14). Essas interlocuções seriam uma ação intencional e metódica, envolvendo conhecimentos específicos, interdisciplinares, conceitos, princípios e objetivos para a construção e apropriação de valores éticos, linguísticos, estéticos e políticos e sólida formação científica, cultural, social em diálogo com diferentes visões de mundo (BRASIL, 2015).

Professores e alunos, para Ponce (2018), são sujeitos relevantes da prática curricular e toda atenção devem lhe ser dada para o desenvolvimento das ações curriculares. Lima et al. (2018) caracterizam os estudantes como agentes geradores de conhecimentos, saberes e significações e que ausentá-los, silenciá-los e ocultá-los nos/dos processos curriculares é invisibilizá-los e inferiorizá-los enquanto sujeitos históricos. Contemplar alunos nesse processo é viabilizar sua importância e "a partir do seu conhecimento, de suas necessidades para que seu desenvolvimento seja completo" (P12), "os alunos precisam ser ouvidos, pois seu aprendizado é melhor quando há o interesse” (P26), “é fazer um elo de ligação entre os alunos, atendendo a necessidade de todos" (P28).

Os apontamentos permitem compreender que trazer os alunos para um lugar central nos currículos significa lançar olhares sobre os saberes e experiências trazidas por eles, nos dizendo como se comunicar com eles, como aprendem, se socializam, se formam e se afirmam enquanto sujeitos sociais, culturais e políticos (LIMA et al., 2018). Conhecer o aluno vai além do cotidiano escolar, é preciso saber quais as especificidades regionais que demanda determinada comunidade, pois o atual currículo já vem com "as propostas do governo prontas, engessadas e devemos atender as necessidades de cada região, diferentes culturalmente e entender e elaborar o currículo de acordo com as necessidades de cada região é importante para continuarmos aprendendo e colaborar com a sociedade" (P08).

A cultura para Tonietto e Garanhani (2017) produz ferramentas comunicativas, informativas e interacionista inovadoras às crianças, possibilitando que a realidade social seja transformada de uma forma diferente, diariamente. A criação de um currículo com aspectos multiculturais, para Neira (2008) reforça a processualidade escolar, oferecendo conhecimentos construídos socialmente sendo reconhecidos e potencializados na/pela escola, trabalhando a partir das culturas dos alunos na cultura escolar, resultando em um produto cultural, distinguindo as práticas corporais, constituindo-se em um fator identitário. 
Desse modo, tal apropriação permite que a criança pertença e integre ainda mais os aspectos constituintes da escola, por meio de sua expressividade cultural, contribuindo para a ampliação e enriquecimento das demais aprendizagens além das curriculares, potencializando o processo de ensino e aprendizagem por meio de suas manifestações corporais culturais.

\subsection{Qualidade Educacional e Curricular}

O currículo é estabelecido como agente direcionador da ação docente a favor da formação de indivíduos. Nele encontramos aspectos históricos, sociais, filosóficos, políticos, econômicos e pedagógicos para suprir as necessidades da sociedade. Porém, predominam interesses daqueles que estão no poder, fato corroborado por Anversa e Souza (2016) ao afirmarem que a Educação Física e todo setor da educação nacional, constitui-se pelos interesses sociais geridos pelo capitalismo e, consequentemente, pelas agências e organismos internacionais que buscam hegemonizar o processo educacional.

Para Lima e Neira (2019) o currículo é um elemento simbólico importante dos grupos no poder, para o projeto social produtor de diferentes efeitos, exemplificam, que décadas passadas, as perspectivas curriculares assumiram uma questão técnica ocultando a dimensão ideológica, se baseando na cultura dominante. Palma, Oliveira e Palma (2015) referem-se ao currículo enquanto um artefato histórico social constituído na interação e generalização dos conteúdos, promovendo interesse e significado aos alunos.

O currículo possui diversos conteúdos à serem transmitidos aos alunos para sua formação no espaço escolar. O currículo "é o saber relacionado com alguma área de conhecimento devidamente organizado, seriado e fundamentado, visando atender as necessidades do público no qual lecionamos. Tal contribuição deve ir ao encontro das necessidades reais, atuais e emergentes da sociedade" (P03).

O documento sistematiza o conhecimento a ser transmitido para os alunos com cautela e preocupação em atingir as suas necessidades, pois, conforme Palma, Oliveira e Palma (2015), o currículo é guiado pelas questões sociais, políticas, culturais e epistemológicas, revelando os interesses da sociedade e da educação, envolvidos na história e em conflitos, é uma luta por prestígio e áreas do conhecimento.

Um currículo quando dotado de pressupostos culturais, transcende fronteiras, conecta manifestações e promove uma análise e compartilhamento de significados em que, se a escola 
for concebida adequadamente para discutir, vivenciar, ressignificar e ampliar a cultura corporal, será possível ansiar pela formação de cidadãos que percebam e critiquem as conjecturas hegemônicas existentes historicamente, impedindo a reprodução de ideologias (NEIRA, 2018).

Dito isso, dar mais qualidade ao currículo significa ampliar a participação da comunidade escolar, pois é "importante, desde que haja preparação da comunidade para esse diálogo, pois sem conhecimento pouco se pode contribuir e poucas opiniões existirão, de fato, virão de encontro as necessidades educacionais da comunidade onde se está inserida. Todos deveriam estar envolvidos na construção dos conteúdos principalmente pais, responsáveis, alunos e comunidade como um todo fazem parte da escola e dela usufruem. Não há como, apenas ficar como coadjuvante de algo imposto, colocado e que por vezes não tem sentido para seu dia a dia. Acredito que com a participação de todos, ideias criativas e inovadoras surgiria e contribuiria" (P18).

Os atuais currículos possibilitam ao professor ampliar os conteúdos culturais a serem transmitidos aos alunos. Conforme Brasil (2017), a construção curricular nas escolas precisa elaborar propostas que considerem as necessidades, possibilidades e interesses dos estudantes, suas identidades linguísticas, éticas e culturais também. Essa flexibilidade curricular otimiza o trabalho docente, possibilitando múltiplas manifestações e práticas corporais. Nessa perspectiva, Anversa e Souza (2016), fomentam que é possível justificar uma Educação Física para além do movimento técnico, é preciso conhecer o movimento e navegar em sua racionalidade técnico instrumental, possibilitando a (re)criação e transformação de gestos, promovendo o processo de formação humana e reinterpretando o movimento para a superação.

\section{CONCLUSÃO}

Pode-se observar, a partir do relato dos professores, que o currículo é um documento que contém interesses para além dos aspectos educacionais, sendo uma ferramenta importante para o trabalho docente, principalmente para o processo formativo educacional dos alunos, sustentando, organizando e direcionando as ações para o desenvolvimento do trabalho, viabilizando a manutenção e ampliação de aspectos voltados para a qualidade da educação no âmbito escolar. 
Por ser um documento essencial para a efetivação da prática docente cotidiana, o currículo tematiza, esquematiza e direciona os conteúdos que o professor precisa apresentar, aplicar, abordar e transmitir ao aluno. Em sua estruturação, os apontamentos dados pelos professores revelam e confirmam a existência de concepções pedagógicas e filosóficas pautadas na construção do sujeito por meio das relações dialéticas existentes entre teoria e a prática. Aproxima o conhecimento da Educação Física e seus eixos estruturantes, Dança, Ginástica, Lutas, Jogos e Brincadeiras e Esportes, construídos historicamente, da realidade dos alunos, com assimilação dos conhecimentos teóricos, práticos e do cotidiano dos alunos.

A análise indicou que para os professores o currículo direciona a ação docente para atender as necessidades dos alunos, principalmente, nos aspectos motores, pois a organização curricular está estruturada e distribuída por temas condizente com a idade e ano escolar, apresentando generalizações e carências sobre demais conteúdos que visam aproximar o aluno do conhecimento humano historicamente construído nas relações sociais e, fragilizado por sua repetitividade conteudista, o currículo foi considerado raso nas questões inerentes às necessidade dos alunos.

Quando bem estruturado, o currículo viabiliza o processo de ensino e de aprendizagem permitindo que aspectos sociais e culturais, peculiares da comunidade escolar sejam inseridos junto às manifestações e práticas corporais nas aulas de Educação Física. Conhecer a comunidade escolar é considerar os aspectos culturais e suas manifestações trazidas pelos alunos para dentro das escolas. É reconhecer e valorizar o conhecimento individual da criança que se torna disseminadora do conhecimento da cultura corporal adquirida no cotidiano, possibilitando a ação docente diante de um contexto pluralizado e essa participação ainda é questão que requer estudos, investigações para compreender a polarização entre os professores.

Elaborar um documento que se destina à formação de indivíduos é considerar especificidades e particularidades, possibilitando a construção curricular participativa. A participação da comunidade externa escolar na construção de um currículo, propicia (re)construir a prática escolar pela aproximação do conhecimento trazido dela. Ainda é necessário estudos e pesquisas mais aprofundadas para essas constatações.

Portanto, verifica-se que o currículo pode proporcionar a melhoria das aulas de Educação Física no ensino fundamental nos anos iniciais ao ampliar a compreensão das ações tomadas nas aulas para a realização do processo de ensino e de aprendizagem e a participação 
Programa de Pós-Graduação em Educação: Currículo

da comunidade escolar potencializa a construção curricular, permitindo considerar as especificidades locais, envolvendo diversos atores internos e externos da escola, aproximando a comunidade das ações escolares e otimizando o processo ensino aprendizagem e essa prerrogativa está inserida na BNCC, na tentativa de valorização da cultura local de comunidade escolar.

\section{REFERÊNCIAS}

ANVERSA, Ana Luiza Barbosa et al. Análise da área de Educação Física Escolar nos periódicos Brasileiros (2010-2015). Pensar a Prática, Goiânia, v. 21, n. 2, p. abr./jun. 2018a. Disponível em: https://www.revistas.ufg.br/fef/article/view/46004. Acesso em: 09 mar. 2020.

ANVERSA, Ana Luiza Barbosa et al. Formação continuada na implementação do esporte educacional na educação física escolar. Pensar a Prática, Goiânia, v. 21, n. 4, out./dez. 2018b. Disponível em: https://www.revistas.ufg.br/fef/article/view/50877. Acesso em: 09 mar. 2020.

ANVERSA, Ana Luiza Barbosa; SOUZA, Vania de Fátima Matias de. Educação em Gramsci: aproximações com o campo da educação física. Práxis Educacional, Vitoria da Conquista, v. 12, n. 23, p. 153-174, set/dez. 2016. Disponível em: https://periodicos2.uesb.br/index.php/praxis/article/download/910/774/1520. Acesso em: 09 mar. 2020.

ARROYO, Miguel Gonzalez. Indagações sobre currículo: educandos e educadores seus direitos e o currículo. Brasília: Ministério da Educação, Secretaria de Educação Básica, 2007.

BOSCATTO, Juliano Daniel; DARIDO, Suraya Cristina. Currículo e Educação Física Escolar: análise do estado da arte em periódicos nacionais. Journal Physical Education, Maringá, v. 28, e2855, p. 1-16. 2017. Disponível em:

https://www.scielo.br/scielo.php?pid=S244824552017000100203\&script=sci_abstract\&tlng=pt. Acesso em:09 mar. 2020.

BRASIL. Ministério da Educação. Secretaria de Educação Fundamental. Parâmetros curriculares nacionais: Educação Física. Secretaria de Educação Fundamental. Brasília. MEC/SEF, 1997.

BRASIL. Ministério da Educação. Conselho Nacional de Educação. Conselho Pleno. Resolução no 2 , de $1^{\circ}$ de julho de 2015. Disponível em: http://portal.mec.gov.br/docman/agosto-2017-pdf/70431-res-cne-cp-002-03072015-pdf/file. Acesso em: 09 mar. 2020.

BRASIL. Ministério da Educação. Conselho Nacional de Educação. Conselho Pleno. Resolução n ${ }^{\circ}$, de 22 de dezembro de 2017a. Disponível em: 
Programa de Pós-Graduação em Educação: Currículo

http://portal.mec.gov.br/index.php?option=com_docman\&view=download\&alias=79631rcp002-17-pdf\&category_slug=dezembro-2017-pdf\&Itemid=30192. Acesso em: 09 mar. 2020.

BRASIL. Ministério da Educação. Base Nacional Comum Curricular: Educação Infantil e Ensino Fundamental. Brasília. MEC/Secretaria de Educação Básica, 2017b. Disponível em: http://basenacionalcomum.mec.gov.br/images/BNCC_EI_EF_110518_versaofinal_site.pdf. Acesso em: 09 mar. 2020.

DE PAULA, Alessandra et al. Inclusão na escola do sistema regular - integração: formação Profissional, currículo e família. Revista Intersaberes, v. 10, n. 20, p.126-141. jan.- abr. 2015. Disponível em: http://docplayer.com.br/17454458-Inclusao-na-escola-do-sistemaregular-integracao-formacao-profissional-curriculo-e-familia.html. Acesso em: 09 mar. 2020.

DOURADO, Luiz Fernandes; OLIVEIRA, João Ferreira. A qualidade da educação: perspectivas e desafios. Cad. Cedes, Campinas, v. 29, n. 78, p. 201-215, mai/ago. 2009. Disponível em: https://www.scielo.br/pdf/ccedes/v29n78/v29n78a04. Acesso em: 09 mar. 2020.

DUARTE, Newton. Sociedade do conhecimento ou sociedade das ilusões? Campinas: Autores Associados, 2008.

FONSECA, Marília. Políticas públicas para a qualidade da educação brasileira: entre o utilitarismo econômico e a responsabilidade social. Cad. Cedes, Campinas, v. 29, n. 78, p. 153-177, mai/ago. 2009. Disponível em: https://www.scielo.br/scielo.php?pid=S010132622009000200002\&script=sci_abstract\&tlng=pt. Acesso em: 09 mar. 2020.

GAMA, Carolina Nozela; DUARTE, Newton. Concepção de currículo em Dermeval Saviani e suas relações com a categoria marxista de liberdade. Interface, v. 21, n. 62, p. 521-30.

2017. Disponível em: https://www.scielo.br/scielo.php?pid=S141432832017005010103\&script=sci_abstract\&tlng=pt. Acesso em: 09 mar. 2020.

GONZALEZ, Fernando Jaime; DARIDO, Suraya Cristina; OLIVEIRA, Amauri Aparecido Bassoli. Práticas corporais e a organização do conhecimento. Maringá: Eduem, 2014.

GONZÁLEZ, Fernando Jaime; SCHWENGBER, Maria Simone Vione. Práticas pedagógicas em Educação Física: espaço, tempo e corporeidade. Erechim: Edelbra, 2012.

HYPOLITO, Álvaro Moreira; VIEIRA, Jarbas dos Santos; LEITE, Maria Cecilia Lorea. Currículo, gestão e trabalho docente. Revista e-curriculum, São Paulo, v. 8, n. 2, p. 1-16, ago. 2012. Disponível em: https://revistas.pucsp.br/curriculum/article/view/10989. Acesso em: 09 mar. 2020.

LIMA, Maria Emília; NEIRA, Marcos Garcia. Formação e atuação no currículo cultural da educação física: fios que se entrelaçam. Revista Ibero Americana de Estudos em Educação, Araraquara, v.14, nº1, p. 208-221, jan/mar. 2019. Disponível em: 
https://periodicos.fclar.unesp.br/iberoamericana/article/view/10888. Acesso em: 09 mar. 2020.

MACHADO, Roseli Belmonte; LOCKMANN, Kamila. Base nacional comum, escola e professor. Revista e-curriculum, São Paulo, v.12, n.03, p.1591-1613, out/dez. 2014. Disponível em: https://revistas.pucsp.br/index.php/curriculum/article/view/21670. Acesso em: 09 mar. 2020.

MALDONADO, Daniel Teixeira; SILVA, Sheila Aparecida Pereira dos Santos. Fundamentação teórica da educação física em propostas curriculares da escola pública de São Paulo: uma análise das abordagens pedagógicas. Educação em Revista, Belo Horizonte, v.34. 2018. Disponível em: https://www.scielo.br/scielo.php?script=sci_arttext\&pid=S010246982018000100180. Acesso em: 09 mar. 2020.

MARANI, Lidiane; SANCHES NETO, Luiz; FREIRE, Elisabete dos Santos. O currículo da Educação Física na rede municipal de Barueri: as Percepções dos professores. Movimento, v. 23, n. 1, p. 249-264. jan./mar. 2017. Disponível em:

https://seer.ufrgs.br/Movimento/article/view/65265. Acesso em: 09 mar. 2020.

MARINGÁ, Prefeitura do município - Secretaria de educação. Currículo da educação infantil e anos iniciais do ensino fundamental. Maringá, 2012.

MATOS, Juliana Martins Cassani et al. Conteúdos de ensino da educação física escolar: saberes compartilhados nas narrativas docentes. Rev. Educ. Fis./UEM, v. 26, n. 2, p.181-199, abr./jun. 2015. Disponível em: https://www.scielo.br/scielo.php?pid=S1983-

30832015000200181\&script=sci_abstract\&tlng=pt. Acesso em: 09 mar. 2020.

MINAYO, Maria Cecilia de Sousa; DESLANDES, Suely Ferreira; GOMES, Romeu. Pesquisa Social, teoria método e criatividade. Petrópolis, RJ: Vozes, 2016.

MOTA E SILVA, Eduardo Vinicius; VENÂNCIO, Luciana. Aspectos legais da Educação Física e integração a proposta pedagógica da escola. In: DARIDO, Suraya Cristina e RANGEL, Irene Conceição Andrade. Educação Física na Escola: implicações para a prática pedagógica. 2. ed. Rio de Janeiro: Guanabara Koogan, 2015. p. 50-63.

NEIRA, Marcos Garcia. A cultura corporal popular como conteúdo do currículo multicultural da Educação Física. Pensar a prática, v.11, n.1, p. 81-89, jan./jul. 2008. Disponível em: https://www.revistas.ufg.br/fef/article/view/1699. Acesso em: 09 mar. 2020.

NEIRA, Marcos Garcia. O currículo cultural da educação física: pressupostos, princípios e orientações didáticas. Revista e-curriculum, São Paulo, v. 16, n. 1, p. 4-28, jan/mar. 2018. Disponível em: https://revistas.pucsp.br/index.php/curriculum/article/view/27374. Acesso em: 09 mar. 2020.

NEIRA, Marcos Garcia; NUNES, Mario Luiz Ferrari. Educação Física, currículo e cultura. São Paulo: Phorte, 2009. 
Programa de Pós-Graduação em Educação: Currículo

PALMA, Ângela Pereira Teixeira Victoria; OLIVEIRA, Amauri Aparecido Bassoli de; PALMA, José Augusto Victoria. Educação Física e a organização curricular: educação infantil e ensino fundamental. Londrina: Eduel, 2015.

PEDON, Nelson Rodrigo; CORREA, Rubens Arantes. Escola e currículo: um ensaio sobre territórios em disputa. Rev. NERA, Presidente Prudente v. 22, n. 48, p. 85-97. 2019. Disponível em: https://revista.fct.unesp.br/index.php/nera/article/download/6366/4855. Acesso em: 09 mar. 2020.

PERINI, Rosiléia; BRACHT, Valter. Os saberes docentes dos professores de educação física na educação infantil de Serra/ES. Pensar a Prática, Goiânia, v. 19, n. 4, p. 953-963, out./dez. 2016. Disponível em: https://www.revistas.ufg.br/fef/article/view/41753. Acesso em: 09 mar. 2020.

PONCE, Branca Jurema. O currículo e seus desafios na escola pública brasileira: em busca da justiça curricular. Currículo sem Fronteiras, v. 18, n. 3, p. 785-800, set./dez. 2018. Disponível em: https://docplayer.com.br/122261330-O-curriculo-e-seus-desafios-na-escolapublica-brasileira-em-busca-da-justica-curricular.html. Acesso em: 09/03/2021.

ROSÁRIO, Luiz Fernando Rocha; DARIDO, Suraya Cristina. A sistematização dos conteúdos da educação física na escola: a perspectiva dos professores experientes. Motriz, Rio Claro, v. 11 n. 3 p. 167-178, set./dez. 2005. Disponível em: https://www.rc.unesp.br/ib/efisica/motriz/11n3/10LRF.pdf. Acesso em: 09 mar. 2020.

RUFINO, Luiz Gustavo Bonatto. O trabalho docente na perspectiva de Professores de Educação Física: análise de alguns fatores condicionantes e suas Restrições para o desenvolvimento da Prática pedagógica. Movimento, Porto Alegre, v. 23, n. 4., p.1257-1270, out./dez. 2017. Disponível em: https://seer.ufrgs.br/Movimento/article/view/66771. Acesso em: 09 mar. 2020.

SANTOS, Boaventura de Sousa. Um discurso sobre a ciência. 8. ed. São Paulo: Cortez. 2018.

SAVIANI, Dermeval. Pedagogia histórico-crítica: primeiras aproximações. 10. ed. Campinas: Autores Associados, 2008.

SCHERER, Renata Porcher e GRAFF, Patrícia. Das adaptações às flexibilizações curriculares: uma análise de documentos legais e revistas pedagógicas. Revista ecurriculum, São Paulo, v. 15, n. 2, p. 376-400, abr./jun. 2017. Disponível em: https://revistas.pucsp.br/index.php/curriculum/article/view/26926/0. Acesso em: 09 mar. 2020.

SILVA, Maria Abádia da. Qualidade social da educação pública: algumas aproximações. Cad. Cedes, Campinas, v. 29, nº 78, p. 216-226, mai/ago. 2009. Disponível em: 
Programa de Pós-Graduação em Educação: Currículo

https://www.scielo.br/scielo.php?pid=S0101-

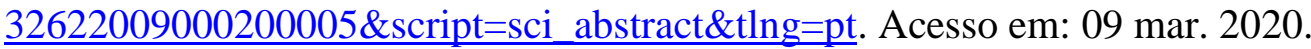

SILVEIRA, Roziele Bovolini, BRITTES, Leticia Ramalho. A Participação Da Família Na Escola: Desdobramentos Sobre a Evasão Escolar e a Educação Profissional e Tecnológica Na Lógica Neoliberal. Educação Básica Revista, v.3, n.1, p.29-46, 2017. Disponível em: http://www.educacaobasicarevista.com.br/index.php/ebr/issue/view/ebrv3n12017/6. Acesso em: 09 mar. 2020.

SOARES, Carmem Lúcia et al. Metodologia do ensino da Educação Física. 2. ed. São Paulo: Cortez, 2012.

TONIETTO, Marcos Rafael; GARANHANI, Marynelma Camargo. A cultura infantil e a relação com os saberes da educação física na escola. Movimento, Porto Alegre, v. 23, n. 2, p. 517-528, abr./jun. de 2017. Disponível em:

https://seer.ufrgs.br/Movimento/article/view/66236. Acesso em: 09 mar. 2020.

WIGGERS, Ingrid Dittrich et al. Um "raio-x" da produção do conhecimento sobre Educação Física Escolar: Análise de periódicos de 2006 a 2012. Movimento, Porto Alegre, v. 21, n. 3, p. 831-845, jul./set. de 2015. Disponível em:

https://seer.ufrgs.br/Movimento/article/view/50517. Acesso em: 09 mar. 2020.

Recebido em: 17/03/2020

Aprovado em: 13/09/2020 